\author{
POR \\ ROLANDO J. ROMERO \\ University of Wisconsin-Milwaukee
}

La obra Farabeuf del escritor mexicano Salvador Elizondo está basada en hechos que a primera vista parecieran históricos. El tema de la obra es un suplicio que se infligía en China a principios de siglo. En chino la tortura se conoce como leng-tch'é o "suplicio de los cien pedazos", porque es un procedimiento en que la víctima es públicamente desollada y descuartizada'. Los personajes de Farabeuf recrean la tortura en una casa en París y en un teatro, treinta o cuarenta años después. Parte de la acción también se lleva a cabo eñ una playa indefinida. Es difícil para el lector determinar si la acción en la playa ocurre a principios o a mediados de siglo. Los personajes principales son: el propio Doctor Farabeuf, cuyo apellido da título al libro de Elizondo, y $\mathrm{Fu} \mathrm{Chu} \mathrm{Li}$, persona objeto del suplicio.

La fotografía del suplicio que Elizondo incluye en su texto tiene una interesante trayectoria bibliográfica. Las fotografías del leng-tch'é fueron reproducidas en un texto que trata de documentar hechos históricos, en un tratado de psicología, en uno de arte y, finalmente, en el de Elizondo, que se puede considerar estrictamente literario. La manipulación de las fotografias del leng-tch'é y de los hechos históricos que rodean el suplicio revelan las preocupaciones individuales de los autores que tratan el tema. El presente trabajo analiza las discrepancias entre los hechos históricos y los ficticios.

\title{
I. HISTORIA
}

El doctor Louis Hubert Farabeuf (1841-1910) es un personaje histórico considerado uno de los grandes maestros de la escuela quirúrgica francesa de su época. Fue profesor de Anatomía en la Facultad de Medicina de París a partir de 1876 y fue miembro de la Academia de Medicina francesa desde 1897.

\footnotetext{
${ }^{1}$ Elizondo no es el único autor hispanoamericano que habla sobre el leng-t'ché. Severo Sarduy lo hace también en su libro Cobra (89), así como Julio Cortázar en Rayuela (70). Toda cita a Elizondo en este artículo, a menos que se especifique otra cosa, refiere a Farabeuf en la edición de Montesinos.
} 
Farabeuf fue autor de varios textos de medicina, uno de los cuales es un Précis de manuel opératoire $(1872)^{2}$.

Parte de la obra de Elizondo se sitúa en China a principios de siglo. En esta época, uno de los eventos históricos más conocidos es la Rebelión de los Boxers, un movimiento anti-extranjero con raíces populares en los tres años que corren entre 1898 y 1901 . Las causas de la rebelión se remontan al siglo XVI cuando los extranjeros empezaron a llegar a Asia. Desde entonces, y por diferentes causas politicas, los chinos combatieron con los países de Occidente. Nunca los extranjeros que vivieron en China se integraron a la cultura local, sino que, por el contrario, cada grupo trató de introducir sus valores, especialmente los religiosos. Es por esto que el sentimiento anti-extranjero muchas veces se manifiestó en un sentimiento anti-religioso. Los Boxers expresaron su resentimiento quemando legiones y asesinando extranjeros y chinos conversos. La dinastía Manchú utilizó el sentimiento anti-extranjero para tratar de librarse de la presencia de los países de Occidente. Estos, arguyendo que el problema que sus ciudadanos tenían con los Boxers era consecuencia del respaldo de la dinastía, atacaron China hasta derrotarla. China firmó el tratado de paz, conocido como "El Protocolo de los Boxers," el 7 de septiembre de 1901.

El centro narrativo de la obra de Elizondo es el suplicio de una persona llamada Fu Chu Li (1880-1905). Fu Chu Li, personaje histórico al igual que el Dr.Farabeuf, se venga del principe Ao Jan Wan, apuñalándolo, por haberle éste quitado su esposa. Los príncipes chinos lo condenan a la pena de muerte por el procedimiento del leng-t'ché.

Históricamente, el periódico Cheng-Pao del 25 de marzo de 1905 publica el decreto imperial en que los príncipes mongoles ordenan el suplicio:

Les princes Mongols demandent que le nommé Fou-Tchou-Li, coupable de meurtre sur le personne du prince Ao-Han-Ouan, soit brulé vivant ${ }^{3}$, mais l'empereur trouve ce supplice trop cruel et condamne Fou-Tchou-Li à la mort lente par le découpage en morceaux. Respect à ceci! (Carpeaux 184).

Los textos de Georges Bataille y de Louis Carpeaux que documentan la tortura no indican el número de página o de columna del periódico donde se publicó el decreto.

El 10 de abril de 1905, a las diez de la mañana, Louis Carpeaux asiste a la plaza Ta-Tché-Ko en Pekín (o Beijing como se conoce actualmente) donde se

${ }^{2}$ En su bibliografía aparecen además los siguientes libros de medicina: Le système sereux, De l'épiderme et des épithéliums, Introduction a l'étude clinique et à la pratique des accouchements.

${ }^{3}$ Según Louis Carpeaux, a la víctima se le forzaba a tomar dos litros de petróleo, se le clavaba un largo pabilo que penetraba casi hasta el estómago al que se le prendía fuego. El su pliciado, al inflamarse el petróleo, escu pía un inmenso chorro de fuego y explotaba ante los asistentes. 
lleva a cabo el suplicio. Carpeaux documenta la tortura con un texto y con cuatro fotografias anónimas tomadas en diferentes etapas del suplició.

En 1932 Georges Dumas publica, en la segunda edición de su Traité de Psychologie, unas fotografías de un suplicio similar al que presenció Carpeaux en Bejing en $1925^{5}$. Estas fotografías, sin embargo, no son las del $\mathrm{Fu} \mathrm{Chu} \mathrm{Li}$ histórico cuyo suplicio documentó Carpeaux. Al ver las fotos, el lector fácilmente puede establecer las diferencias, ya que los sometidos a suplicio, los verdugos y el lugar del suplicio en las dos series fotográficas son distintos. El torturado en las fotos de Dumas es más delgado y el trasfondo del suplicio es diferente, lo que indica que la plaza no es la de Ta-Tché-Ko. Las fotos de Dumas están retocadas y recortadas, concentrándose en la propia figura del sentenciado, sobre todo en el rostro. Dumas señala que las fotografías de la tortura fueron tomadas cerca de medio siglo antes, lo que las fecharía en la década de 1880. Dumas no menciona el decreto, el nombre de la víctima, ni el país donde se lleva a cabo la tortura. Sólo indica, con una nota a pie de página, que el país donde fueron tomadas las fotografías había abolido ese tipo de suplicio. Dumas informa que las fotografías se las proporcionó un tal doctor Desfosses. No conocemos, entonces, la identidad real del condenado de Dumas ni la causa por la que se le tortura.

Georges Bataille, en 1961, también publica, en su Les larmes d'Eros, la misma serie de fotografías que aparecen en el texto de Dumas ${ }^{6}$. Las fotos de Bataille no están retocadas ni recortadas como lo están las de Dumas, por lo que es posible ver las tareas de los verdugos sobre el torturado. Acerca de la primera foto de la serie, Dumas dice que fue tomada antes de dar comienzo al suplicio, por esto no se observa ninguna expresión de dolor. Ya que la fotografía sólo permite ver el rostro y parte de los hombros del sentenciado, el lector no tiene por qué cuestionar loque Dumas escribe. La fotografía de Bataille, sin embargo, contradice directamente esta aserción, ya que es evidente que parte del pecho de la víctima ha sido desollada.

La otra discrepancia entre Bataille y Dumas es la fecha del suplicio del desconocido. Bataille, creyendo que las fotos son las de la tortura del Fu Chu Li histórico, parece dudar de la fecha del suplicio que proporciona Dumas (la década de 1880), ya que Carpeaux había sido testigo de la tortura de $\mathrm{Fu} \mathrm{Chu} \mathrm{Li}$ en 1905. Pero, si tomamos en cuenta que el leng-tch'é es abolido el 24 de abril de 1905, dos semanas después del suplicio de $\mathrm{Fu} \mathrm{Chu} \mathrm{Li}$, es improbable que en ese período haya habido otra tortura similar ${ }^{7}$. Todo indica entonces que las dos

\footnotetext{
${ }^{4}$ Las fotos aparecen en las páginas 180, 204, 216 y 240 del libro de Carpeaux.

${ }^{5}$ Las fotos aparecen en las páginas 283-286 del tratado de Dumas. Bataille cita la edición de 1923 del Tratado de psicologta de Dumas, pero esa edición no contiene ninguna fotografía, donde si aparecen es en la edición ampliada del Tratado publicado en 1932. ${ }^{6}$ Las fotos aparecen en las páginas 232-234 del libro de Bataille.

${ }^{7}$ Modern China: A Chronology from 1824 to the Present. Londres: Thames and Hudson, 1982; Carpeaux 190.
} 
series de fotografias fueron tomadas en diferentes suplicios: las fotos de la tortura de $\mathrm{Fu}$ Chu Li presenciada por Carpeaux fueron tomadas el 10 de abril de 1905 y las del suplicio del desconocido publicadas primero por Dumas y posteriormente por Bataille, en la década de 1880. Bataille informa que un tal doctor Borel le proporcionó las fotos.

Bataille acompaña sus fotografias del suplicio del desconocido con el texto del decreto que ordena el suplicio del $\mathrm{Fu}$ Chu Li histórico. Estos datos son aparentemente tomados de Carpeaux (el por qué del suplicio, la fecha, el decreto, la publicación del decreto), aunque las fotografías no corresponden alas del Fu Chu Li histórico.

Salvador Elizondo toma una de las fotografías del suplicio de Les larmes d'Eros de Bataille y la hace parte integral de su texto. Farabeuf, publicada por Joaquín Mortiz en México en 1961, es la ficcionalización de esa fotografía ${ }^{8}$.

\section{FICCION}

El Dr. Farabeuf de Elizondo mantiene una estrecha aunque no exacta relación con el personaje histórico. El médico, también catedrático de la Escuela de Medicina, "era un personaje oscuro, frecuentador de ciertos círculos reaccionarios" (Elizondo 93). Farabeuf había estado en China con la Fuerza Expedicionaria y había sido aficionado a la fotografía; con los aparatos de principios de siglo logra fotografiar el suplicio. El Farabeuf ficticio es autor de dos libros: Précis de manuel opératoire (Elizondo 68) y Aspects médicaux de la torture (Elizondo 131) en que analiza el leng-tch'é. En la bibliografía del Farabeuf histórico no aparece el texto que le atribuye el narrador, Aspects médicaux de la torture. Históricamente tampoco se sabe si el doctor H. L. Farabeuf estuvo en China, ya que las fuentes históricas que hablan del leng-tch'é no lo mencionan.

El Fu Chu Li de Elizondo es un Boxer que asesina al príncipe Ao Jan Wan por aliarse con las potencias extranjeras. Puesto que Elizondo toma la fotografía del texto de Bataille, la persona que allí aparece no es el $\mathrm{Fu} \mathrm{Chu} \mathrm{Li}$ histórico cuyo suplicio presenció Louis Carpeaux. Además, históricamente, entre la rebelión de los Boxers y la tortura de $\mathrm{Fu} \mathrm{Chu}$ Li median cerca de cuatro años. No es por lo tanto extraño que ninguna de las fuentes que documentan el suplicio histórico hable de los Boxers. En Farabeuf la tortura se lleva a cabo, no la mañana del 10 de abril de 1905, sino la tarde del 29 de enero de 1901, fecha en que, en la obra, el doctor Farabeuf se encontraba en China (Elizondo 99).

En Farabeuf la fuente del texto del decreto es el North China Daily News del 29 de enero de 1901, página 3, columna 7. Según el narrador el decreto aparece en los periódicos Ch'eng pao (históricamente cierto) y Shuntien sh'pao.

\footnotetext{
${ }^{8}$ La fotografía en el texto de Elizondo, en la edición de Joaquín Mortiz aparece en el capítulo 7, en la edición de Montesinos aparece en el capítulo 2.
} 
El decreto es el siguiente:

Los príncipes Mongoles exigen que el ... Fu Chu Li, culpable de homicidio en la persona del Príncipe Ao Han Wan, sea quemado vivo, pero el Emperador, considerando [la] pena demasiado cruenta, condena, en su infinita misericordia, a Fu Chu Li [a la] muerte lenta por el procedimiento de [Leng]-Tch'é. ¡Cúmplase!

La única diferencia entre el decreto histórico y el que podemos reconstruir en Farabeuf es la palabra ausente "nombrado".

\section{ESCRITURA, CIRUGIA Y SUPLICIO}

$\mathrm{Al}$ analizar las discrepancias entre los datos históricos y los ficticios, resulta obvio que la intención de Elizondo es acoplar la historia a sus propios fines estéticos. Por ejemplo, aunque históricamente $\mathrm{Fu} \mathrm{Chu} \mathrm{Li} \mathrm{y} \mathrm{el} \mathrm{doctor} \mathrm{Farabeuf}$ nada tienen que ver entre sí, Elizondo los relaciona para hacer del trabajo quirúrgico una metáfora del suplicio, y de ambos, metáforas de la escritura.

El narrador escribe que "el suplicio es una forma de escritura" (Elizondo 135). Pero el trabajo quirúrgico del doctor Farabeuf es similar al de los verdugos que torturan a Fu Chu Li: "Su inquietud, maestro, proviene del hecho de que aquellos hombres realizaban un acto semejante a los que usted realiza en los sótanos de la Escuela ..." (Elizondo 71). La relación entre los verdugos y el torturado es similar a la del médico con los pacientes. Establecida esta relación los términos son intercambiables: los verdugos son médicos y la víctima es un paciente: “EI paciente ofrece resistencia a sus médicos?” “-No; el paciente se abandona al suplicio" (Elizondo 140).

Ya que el suplicio es "una forma de escritura" y es también una operación quirúrgica encaminada por un lado a demostrar y por el otro a investigar, entonces la escritura tiene el mismo propósito que la operación quirúrgica. Por esto el suplicio-operación médica, al igual que la escritura, se inicia con palabras:

- Cuéntame todo. ¿Cómo se inicia el tratamiento?

- Con palabras.

-Qué palabras?

-Palabras lentas, como las que profiere la ouija. Primero le hacen dos tajos horizontales en las tetillas (Elizondo 140).

Asociar la cirugía con la escritura no es nuevo ya que el doctor Farabeuf histórico, en su estudio Précis de manuel opératoire indica que el bisturi debe sostenerse de la misma forma en que se sostiene un lápiz. Tenemos que suponer

9 Este dato es importante ya que "nombre" en francés quiere decir "número". Los números, como lo veremos en la sección IV de este trabajo, son importantes en Farabeuf. 
que Elizondo está al tanto de la relación entre el bisturí y el lápiz, ya que menciona el Précis en Farabeuf.

En la metáfora escritura-suplicio-operación quirúrgica, la pluma-cuchillobisturí (o escalpelo) va haciendo incisiones o tajos que a su paso dejan sangretinta (escritura) ${ }^{10}$. Los cortes ponen al descubierto el interior del cuerpo; en el caso de la pluma, el interior de los personajes. El lector sabe cómo son los personajes sólo por los trazos-heridas que la pluma deja sobre el papel. La operación se lleva a cabo en el quirófano o en el anfiteatro. En éste hay espectadores, son ellos las figuraciones del lector. El verdugo o médico es el equivalente del escritor. La página en blanco representa el cuerpo sobre el que trabaja. La novela representa entonces el laboratorio que sirve para la exploración, es el quirófano o anfiteatro mismo.

El concepto de novela como laboratorio no es nuevo, está presente al menos desde el naturalismo con la publicación del libro del doctor Claude Bernard Introduction a l'étude de la médecine expérimentale, en el que se basa Emile Zola para desarrollar su concepto de "novela experimental". El narrador en la obra de Elizondo compara específicamente Aspects médicaux de la torture, en el que el doctor Farabeuf estudia el leng-tch'é, con el libro del doctor Bernard(Elizondo 29). El método experimental como lo define Zola, consiste no en la observación pasiva, sino en el tratar, bajo una situación controlada, de recrear relaciones que se dan en la naturaleza. El laboratorio es entonces una figuración de la naturaleza misma, el científico es su semi-dios. Según Zola, el anhelo del cientifico es controlar para poder dirigir. Los científicos-novelistas no crean, solamente manipulan las relaciones ya dadas en la naturaleza que ellos recrean bajo diferentes condiciones. El novelista, dice Zola, debe operar en los personajes y sus pasiones de la misma manera en que el fisiólogo opera en seres animados hasta llegar a la causa inicial de la que emanan todas las otras relaciones más complejas. La única contribución del científico-novelista es un a priori, una tesis con la cual poder experimentar.

Es claro que en Farabeuf el a priori experimental es el suplicio, es de él que emanan todas las otras relaciones. El centro narrativo, la tortura de $\mathrm{Fu} \mathrm{Chu} \mathrm{Li}$, es la causa de todas las otras relaciones que vendrán luego. La labor del narrador consiste entonces en experimentar con ese mismo suplicio desde diferentes vertientes: el suplicio por amor, el suplicio religioso, el suplicio erótico, el suplicio como farsa, el suplicio político, etcétera. Los diferentes niveles narrativos en Farabeuf no son más que relaciones adicionales, condiciones que el narrador crea para obtener diferentes resultados. Y el narrador no tiene que dar ninguna explicación sobre el por qué de las diferentes situaciones. Su labor es simplemente la de operar en sus personajes, poner al descubierto sus pasiones, sus deseos, sus anhelos.

${ }^{10}$ En El hipogeo secreto Elizondo hace referencia a un "lápiz sangrante de escrituras" (Elizondo, Hipogeo 110). 
El otro tipo de cirugía que practica el doctor Farabeuf en la morgue de la Escuela de Medicina es la de investigación:

-Mire usted ... - dijo el maestro Farabeuf reteniendo con firmeza entre sus dedos los separadores manchados de excrecencias y de sangre medio coagulada mientras con la otra mano, blanquísima y afilada, iba señalando con la punta de un canalizador los órganos y los tejidos que su destreza iba descubriendo poco a poco en el interior de aquel hombre a quien alguien había asesinado en la noche (Elizondo 54).

Esta "cirugia" es simplemente la autopsia, encaminada a determinar las causas de la muerte. Pero es practicada sobre seres muertos, por lo que las oportunidades para experimentar son limitadas. Esto explica, desde el punto de vista médico, la fascinación de Farabeuf por practicar el mismo tipo de operación sobre una persona viva. El equivalente de este tipo de cirugía es la escritura investigativa, la disección ${ }^{1}$ ?

... la facultad de escribir recobrada ... no es dolorosa o complicada; es ardua y fastidiosa: consiste en la disección (enfásis nuestro) por la atención y la escritura, de la obsesion inolvidable o de la idea fija. Todavía tiembla, asido débilmente por las falanges tumefactas, el filoso escalpelo; la pluma-fuente con que pongo al descubierto, más al capricho de la memoria que al dictado de los preceptos de la anatomía descriptiva de los personajes literarios la figura de aquel hombre en la playa (Elizondo, Camera lucida 11) ${ }^{\mathbf{2}}$.

\footnotetext{
${ }^{11}$ Fouques también establece la relación entre escritura y disección en su artículo.

12 El hombre en la playa es Robinson Crusoe, aditamiento literario para significar la exploración y el aislamiento a la vez. Esa exploración se da en Crusoe por medio del método de observación, es así como el personaje de Defoe va ensanchando sus contornos. Otro aditamiento literario en Elizondo es la estatua de Condillac que explora sus derredores, pero el método de investigación no es el de observación sino el de la meditación.

Elizondo hace uso de la metáfora lápiz-escalpelo en otro texto:

“... algunos instrumentos metálicos que alguien había dejado sobre la mesilla brillan como la punta de un lápiz-tinta- hacen pensar que se trata de un quirófano infame o de un anfiteatro para la demostratio de la anatomía descriptiva ( $E l$ grafografo 36 ).
}

Walker Percy, en un ensayo reciente titulado "The Diagnostic Novel: On the Uses of Modern Fiction" establece una relación entre la medicina y la novela ya que, según él, ésta últimamente se practica como método de exploración similar al método que el llama científico:

... all fiction can be used as an instrument of exploration and discovery, in short of sciencing. In a new age, when things and people are devalued, when meanings break down, it lies within the province of the novelist to start the search afresh, like Robinson Crusoe on his island. The novelist or poet in the future might be able to discover, or rediscover, how it is with man himself, who he is, and how it is between him and other men (Walker 45).

Las ilustraciones del artículo de Walker hacen uso de la metáfora escritura-cirugía: una de las manos sostiene una pluma que deja a su paso una incisión roja que gotea sangre. 
Si la escritura para Elizondo es instrumento, no lo es de persuasión y comunicación sino de investigación. Es por medio del lenguaje, de la escritura, que el escritor abre el cuerpo del libro; lo potencial de la obra es expuesto por medio de la escritura. Pero al abrir la obra la destruye, por lo tanto la escritura no comunica, sino simplemente expone.

La escritura, en cuanto sangre o herida, señala la falta de comunicación (muerte) y es desde esa muerte que se genera.

Irónicamente, ya que la escritura no sirve como instrumento de comunicación, el problema del lector siempre está presente. Hay figuraciones demasiado claras de los espectadores/receptores en Farabeuf: los espectadores de la plaza en China, los estudiantes en el anfiteatro de la Escuela de Medicina, las figuras en el espejo. Pero son participantes pasivos, voyeurs que observan sin cuestionar. La lectura de Farabeuf, por lo tanto, se puede equiparar a la labor en el anfiteatro. El lector, pasivamente, observa la operación del escritor sobre el cuerpo del libro. Poco a poco el escritor expone las partes interiores de la muñeca china. Tras de la primer capa diegética (el doctor que llega a la casa y entra a ella para llevar a cabo su parte en un convenio) el lector se da cuenta de que tras de ese hecho se encuentran otros: la escena en la playa, la tortura de Fu Chu Li, etc. Mediante la labor de disección y la observación se exponen las otras capas narrativas, hasta llegar a la fuente: el suplicio de una persona en China. El cuerpo del texto de Elizondo consiste de nueve capítulos que el lector desmembra uno por uno hasta llegar al final.

El lector, por lo tanto, también participa en la labor de destrucción. En cuanto receptor participa en la disección, ve cómo el escritor abre el cuerpo de la obra y la expone. Pero al hacerlo destruye la novela. El cuerpo de la obra no se puede volver a reconstruir, la labor de disección es destructiva, no construye. No es un rompecabezas que se puede volver a armar; es un cuerpo vivo que en el proceso de la lectura se queda sin vida. La lectura lleva a la muerte, no a la vida. La lectura no produce; el lector no es la tierra en que crece la semilla de la vida sino un simple espectador que observa al escritor experimentar sobre el cuerpo de la obra.

\section{SINTESIS DE LOS OPUESTOS}

La manipulación de los hechos históricos se explica también en función de la filosofía de los opuestos. El narrador de Farabeuf insiste mucho en las dualidades antagónicas: el "si" y el "no" de una ouija, "El amor profano y el amor sagrado" de una pintura de Tiziano, el color blanco del uniforme de enfermera de una mujer y el negro del vestuario de otra. Se contraponen, además, el amor y la muerte, el orgasmo y la tortura, la derecha y la izquierda. Otras menciones específicas a las dualidades son: maloliente y perfumado, presente y pasado, recuerdo y experiencia, vida y muerte, día y noche, goce y suplicio -y sus 
variaciones, placer y tortura, placer y dolor, orgasmo y dolor, orgasmo y muerte. Esta contraposición es la más constante.

La fuente de donde emanan las dualidades antagónicas está expresada, desde la primera página de Farabeuf, por medio de "las líneas continuas y las líneas rotas, los yang y los yin ...." (Elizondo 10). El yin y el yang, como ya sabemos, son también la base filosófica de uno de los libros clásicos chinos, el $I$ Ching o Libro de las mutaciones.

Sabemos que el yang se asocia con la claridad y el yin con la oscuridad, pero adicionalmente el I Ching asigna valores numéricos a las dualidades. El seis y ocho son yin, el siete y nueve son yang. Los yin y yang también pueden encontrarse en una etapa de transformación, por ejemplo, al amanecer, cuando la oscuridad se empieza a mezclar con la luz del día, o al anochecer, cuando la luz del día se hace menos clara. Más especifícamente entonces, el número seis representa el yin en transformación, el ocho representa el yin estable, el siete representa el yang estable y el nueve el yang en proceso de cambio.

Elizondo, con relación al I Ching no se limita a enumerar opuestos en Farabeuf.

Específicamente asocia al verdugo y a su víctima con los números seis (el yin en transformación) y nueve (el yang en proceso de transformación). Hay muchas insistencias en Farabeuf con respecto a la importancia del número seis. Son seis los verdugos que torturan a $\mathrm{Fu} \mathrm{Chu} \mathrm{Li}$, uno de los personajes traza el ideograma chino liú (que quiere decir "seis") en la ventana. El narrador describe a los verdugos como una máquina hexagonal, se habla de un juego de esferas de seis niveles con seis orificios en cada nivel.

El seis, según el I Ching es el número del yin, y el yin representa la oscuridad. Al doctor Farabeuf se lo describe como una sombra (Elizondo 154); además, en la recreación del suplicio, es él quien toma el lugar de los seis verdugos. Dos de los personajes asocian el ideograma liú con el médico, ya que cuando uno de ellos traza el signo, al estar en la casa en París, en el vaho de la ventana pudo observar al médico a través de él cruzar la calle (Elizondo 52): "la mirada de Farabeuf se ha quedado grabada como un garabato siniestro" en la ventana (Elizondo 101). Según el texto, el número seis tiene un significado especial: “¿Quién dibujó en la noche esa figura en la que se concentra el último significado [énfasis nuestro] de una cifra inquietante: el número seis?" (Elizondo 167).

Ya que el ideograma liú representa la muerte _-_... la muerte no es sino un conjunto de líneas que tú, en el olvido, trazaste sobre un vidrio empañado" (Elizondo 135) - y liú quiere decir "seis"; el seis también representa la muerte. Esto no tiene nada de original, ya que las sombras, la oscuridad, la noche, elementos asociados con el médico, no son más que metáforas de la muerte. También dentro de la obra es Farabeuf quien acarrea la muerte. Elizondo, al asociar directamente al doctor Farabeuf con el número seis, pretende que el lector vea al médico como el yin en transformación. 
También por medio del $I$ Ching llegamos a la conclusión de que el torturado está asociado con el número nueve. Los yin y losyang, en el IChing se combinan para formar una serie de imágenes llamadas hexagramas. Estos hexagramas están numerados del número uno al 64 , y los nombres de los hexagramas señalan su simbología. Si tomamos en cuenta que el torturado se llama Fu Chu $\mathrm{Li}$, y que el hexagrama $\mathrm{Fu}$ (El Retorno) es el número 24 (cuyos números suman 6), mientras que el hexagrama Li (Lo Adherente) es el número 30 (cuyos números suman 3), el número que corresponde a $\mathrm{Fu} \mathrm{Chu} \mathrm{Li} \mathrm{es} \mathrm{el} \mathrm{numero} 9$ (= $6+3)^{13}$.

Por el énfasis que en Farabeuf se da al número 69, llegamos a la conclusión de que tanto el número seis del yin como el número 9 del yang, debieran de estar unidos. La tortura de Fu Chu Li dura 69 segundos. También la unión sexual del hombre con la mujer dura 69 segundos. El número 69 es también un símbolo casi visual del tai ch"i o el dibujo que en la filosofía del I Ching simboliza la totalidad, la coincidencia de los opuestos ${ }^{14}$.

Yes en realidad a esta coincidencia de los opuestos a donde Elizondo quiere llegar. Por ejemplo, la dualidad hombre/mujer en Farabeuf pretende solucionarse en la androginia, ya que se da como posibilidad que la persona torturada sea"... una mujer ... una mujer bellísima... la mujer-Cristo" (Elizondo 151). Puesto que Cristo es masculino, si la persona torturada es mujer, se unen la feminidad y la masculinidad. Además, siendo el cristianismo una religión occidental, en el "Cristo chino" se manifiestan las culturas del Oriente y del Occidente. Dos religiosos en la obra, un hombre y una mujer, tienen casi el mismo nombre (Paul Belcour y Paule du Saint Esprit). Los contrarios vida y muerte se unen en la fotografía del suplicio de $\mathrm{Fu} \mathrm{Chu} \mathrm{Li,} \mathrm{ya} \mathrm{que} \mathrm{fue} \mathrm{tomada,}$ según el narrador de Farabeuf, en el preciso momento en que el hombre muere (Elizondo 149). Además, uno de los personajes exclama: "Mi identidad te inquieta porque en tu entrega confundí tu vida con tu muerte y pensé que ambas eran la misma cosa" (Elizondo 169).

Los contrarios derecha-izquierda se unen en la perspectiva. La mujer joven frente al muro que da a la calle dibuja el ideograma en la ventana del lado derecho del salón. Sin embargo, Farabeufla ve del lado izquierdo desde la acera de enfrente al prepararse a cruzar la calle. Pero la más presente de las dualidades suprimidas es aquella que opone el dolor al placer en sus diferentes manifestaciones. Expresiones tales como "el dolor, de tan intenso, se convierte de pronto en un orgasmo" (Elizondo 141); "hay un punto en el que el dolor y el

\footnotetext{
${ }^{13}$ Ninguno de los hexagramas se llama "Chu", aunque el propio I Ching se conoce como el Chou I (La mutaciones de los Chu), puesto que el texto procede de los comienzos del reinado de la dinastía de los Chou (1122-221 A.C.).

${ }^{14}$ El tai ch'i es un círculo subdividido en luz y tieniebla, representaciones del yin y del yang: (O I Ching 67, Granet 280.
} 
placer se confunden" (Elizondo 148); el paroxismo del dolor "está colocadojusto en el punto que 'a tortura se vuelve un placer exquisito" (Elizondo 43).

La coincidencia de dolor y placer explica la razón por la cual Dumas, Bataille y Elizondo se interesaron tanto por la fotografia histórica de la tortura. La expresión de dolor en el rostro del torturado no se diferencia de una de placer, y por lo tanto, visualmente enfatiza la simbiosis dolor/placer. Bataille escribe en Les larmes d'Eros:

What I suddenly saw, and what imprisoned me in anguish - but which at the same time delivered me from it- was the identity of these perfect contraries, divine ecstasy and its opposite, extreme horror ${ }^{15}$.

Dumas, en el capítulo de su tratado de psicología titulado "La douleur et le plaisir", opina que bien pudiera ser que el dolor y el placer, que nos parecen opuestos, no sean más que fenómenos de una misma naturaleza (Dumas 251). La fotografía en Farabeuf muestra claramente, mejor que la manipulación de los hechos históricos, la razón por la cual Elizondo la hace parte de su obra. La foto del texto de Elizondo es la tercera de la serie. En ella la víctima atada a la estaca mira hacia el cielo con una expresión en que es obvio el dolor pero que, si al verlo el lector se concentra en el rostro, no se diferencia la expresión de dolor de una de placer. Esta expresión está presente sólo en la tercera fotografía de la serie, lo cual explica por qué la escogió el autor. Ya que la expresión del rostro del torturado pareciera que une el éxtasis al dolor, Elizondo se sirve de ella como aditamiento visual de su tesis sobre la coincidencia de los opuestos, el yin y el yang que en su alternancia generan la totalidad, el Tai ch'i o el principio original.

\section{EL CUADRO MAGICO}

La tercera razón por la cual Elizondo modifica los hechos históricos está también relacionada con el I Ching. En este libro los números tienen especial importancia. Para dibujar los yin y los yang de los hexagramas se necesita hacer uso de los números. Los propios hexagramas están numerados del uno al 64 . Las especulaciones numerológicas se iustifican en el propio I Ching, puesto que, según ese texto, desempeñaron un papel importante, especialmente durante el reinado de la dinastía Han (202 A.C. a 9 D.C.). Este tipo de especulaciones se conecta directamente con una de las secciones de otro de los libros clásicos chinos, el Shu Ching (I Ching 396) ${ }^{16}$. La sección del Shu King se conoce como el "Hung Fan", que significa "Gran modelo" o "Plan supremo".

\footnotetext{
${ }^{15}$ Esta cita es de la edición en inglés. The Tears of Eros, traducida por Peter Connor. San Francisco: City Light Books, 1989. 207.

${ }^{16}$ Shu King en español significa "Libro de los documentos históricos".
} 
Dios, según la leyenda reveló el "Plan supremo” al Gran Yü en la caparazón de una tortuga que salió de las aguas del Río Lo ${ }^{17}$. La caparazón contenía marcas muy definidas del uno al nueve. Yü descifró las marcas y sus números y pudo así reconstruir las nueve divisiones del "Plan supremo" (Granet 138). Granet escribe que Dios otorgó al Gran Yü, por medio del "Plan supremo," la letra misma, el plano del universo representado en los números (Granet 175). Puesto que el "Plan supremo" proviene directamente de Dios, Marcel Granet opina que éste, al igual que el I Ching, contiene un saber y poder total capaces de evocar el orden universal dentro del plano terrestre ${ }^{18}$.

El I Ching conecta directamente los números, agrupados en un diagrama que se conoce como "cuadro mágico", con la filosofía del yin y del yang (I Ching 398).

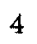

3

8
9

5

1
2

7

6

Los números de este "cuadro mágico" están agrupados en torno al número cinco y si se los suma vertical, horizontal o diagonalmente el total es de quince. También los opuestos diagonales ( 2 y 8,4 y 6) y los verticales (9 y 1) y horizontales ( 7 y 3 ) del centro suman diez. A causa de estas relaciones numéricas, el cuadro, al igual que los designios divinos, es armónico.

La cultura china concede especial importancia a los números cinco y nueve. Son nueve las divisiones del "Plan Supremo" descifrado con la ayuda de las nueve marcas que aparecían en la caparazón de la tortuga. Según Granet, el cinco representa el puesto soberano y el centro del universo (Granet 174) porque no es sólo el centro en el cuadro mágico sino que ocupa entre el uno y el nueve el lugar central (Granet 162). El número cinco en la cultura china es también el símbolo de la totalidad (Granet 168).

Con esta información podemos ahora volver a Farabeuf. La obra de Elizondo contiene nueve capítulos, equivalentes a las nueve divisiones del "Plan supremo". Adicionalmente el número que corresponde al torturado $\mathrm{Fu} \mathrm{Chu} \mathrm{Li}$

\footnotetext{
${ }^{17}$ Por eso el diagrama se conoce también como el Lo Shu.. Lo Shu significa "escritura del río Lo".

${ }^{18}$ Elizondo está al tanto de la relación "Plan supremo," I Ching, cuadro mágico. Su cuento "La historia según Pao Cheng" comienza con estas palabras: "En un día de verano ... el filósofo Pao Cheng se sentó a la orilla de un arroyo a adivinar su destino en la caparazón de una tortuga" (Elizondo, Narda 102). El cuento luego se convierte en una ficcionalización del aspecto teleológico de la escritura.
} 
es también el nueve. La relación con el número cinco es un poco más complicada. Como mencionamos anteriormente, ninguna de las fuentes históricas documenta la página y columna exacta donde aparece publicado el decreto que ordena el suplicio de Fu Chu Li. Sin embargo, el narrador de Farabeufindica que el texto aparece en el North China Daily News del 29-I-1901. La suma de estos números $(2+9+1+1+9+0+1)$ es de 23 , que a su vez suman $5(2+3)$. Además, el texto aparece en la página 3 , columna 7 . Tenemos entonces varios números: el 3 del número de la página, el 5 de la fecha del suplicio y el 7 de la columna del periódico. Como vemos, estos números son exactamente los mismos de la serie central del cuadro mágico.

Farabeuf documenta también la serie inferior del cuadro mágico. El record de amputación de la pierna de la cadera es de " 1 minuto 8 segundos" (Elizondo 36). Elizondo no sólo escribe los números 1 y 8 , sino que, si observamos que un minuto ocho segundos equivale a 68 segundos, de pronto surge también el numero 6. La frase " 1 minuto 8 segundos" incluye a los números 6,1 y 8 . Estos tres numeros surgen tambien de otra manera. $\mathrm{El}$ acto sexual dura

... canónicamente un minuto nueve segundos de acuerdo con el precepto $a b$ intromissio membri viri ad emissio seminis inter vaginam, un minuto ocho segundos para los movimientos propiciatorios y preparatorios: un segundo para la emissio propiamente dicha ... (Elizondo 60).

Los números asociados con la amputación, 6 y 8 , se transforman en $68+1$ del acto sexual. Podemos ahora ver claramente que la serie $6,1,8$ del cuadro mágico está también cifrada en el texto.

El número 9, asociado con $\mathrm{Fu} \mathrm{Chu} \mathrm{Li}$, no es parte de ninguna serie. $\mathrm{Si}$ tomamos en cuenta que el centro del cuadro mágico es el número 5 y que el número cinco representa también la suma de la fecha en que se llevó a cabo el suplicio, nos damos cuenta de que toda la obra Farabeuf gira hacia ese número. Los personajes re-escenifican la tortura queriendo hacer surgir el número 5 . El número 5 está también representado en la estrella de mar que la mujer encuentra en la playa y que, asqueada, arroja lejos de sí. La estrella de mar tiene por lo general la forma de un pentágono, figura que en la cultura occidental asociamos con el número 5 .

Con esta información es posible reconstruir el ideograma liú.. Si en el cuadro mágico dibujamos líneas desde el número cinco hacia cada uno de los números que podemos reconstruir en Farabeuf creamos una imagen casi visual del ideograma liú::

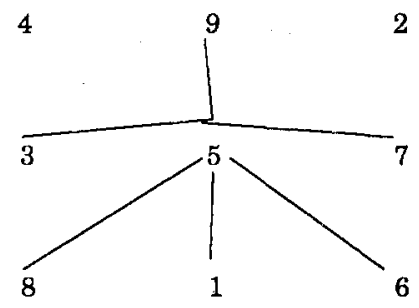


La línea que va del 5 al 1 puede verse simplemente como la representación de la estaca a la que está sujeto el torturado.

El ideograma, a su vez, es una representación de los verdugos, del torturado y de una estrella de mar. El narrador escribe:

La disposición de los verdugos es la de un hexágono que se desarrolla en el espacio en torno a un eje que es el supliciado. Es también la representación equívoca de un ideograma chino .... Mira este signo:

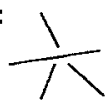

Es el número seis y se pronuncia liú. La disposición de los trazos que lo forman recuerda la actitud del supliciado y también la forma de una estrella de mar, ¿verdad? (Elizondo 153).

El lector, al reconstruir el ideograma dentro del cuadro mágico, en realidad re-escenifica la tortura, y une los verdugos, el ideograma liú, el número seis, el sujeto a quien se suministra el suplicio, la estrella de mar y el número 5 . Todo Farabeuf, como lo especifica el propio narrador, no es sino la "dramatización de un ideograma".

\section{CONCLUSION.}

Es obvio que Salvador Elizondo en Farabeuf se da a la tarea de reconstruir la historia, y de acoplarla a sus fines estéticos. Aunque muchos de los novelistas actuales incorporan la historia en su ficción, la re-escritura histórica va atada a fines de persuasión o compromiso político. En Elizondo, sin embargo, la reescritura histórica va asociada a una búsqueda casi existencial y a un cuestionamiento del ser supremo y sus designios. Es por esto que las "escrituras" divinas están enfáticamente presentes en Farabeuf: el cuadro mágico y el $I$ Ching que, según la cultura china, señalan los designios de Dios sobre la tierra. El I Ching es un método de "a-divinación," esto es, un sistema que permite a la persona llegar a conocer los planes "divinos". La historia misma, en su aspecto teleológico, si aceptamos los asertos de Jorge Luis Borges no es sino"la escritura de Dios". Estas escrituras, sin embargo, muestran la ausencia del ser divino, y quien pretende descifrarlas y entenderlas intenta de cierta manera comunicarse con Dios. En Elizondo sin embargo no se da ningún tipo de entendimiento de las escrituras divinas. Ni la ouija ni el IChing apuntan a una sola respuesta. Tampoco Elizondo acepta simplemente lo ya escrito, su papel no es el de un simple lector o adivino. El autor se da a la tarea de re-hacer la escritura divina. Super-impone, por ejemplo, un ideograma en el cuadro mágico, como si cuestionara el papel del ser humano dentro de los designios divinos; en su novelalaboratorio experimenta y hace el papel de Dios. La obra de Elizondo, más que 
un intento de comunicarse con Dios representa un desafio, la torre de Babel es su metáfora. Pero, como la torre de Babel, el castigo es la proliferación de las maneras de comunicar, por lo que Farabeuf carece de significado unívoco.

\section{OBRAS CITADAS}

Bataille, Georges. Les larmes d'Eros. Paris: Jean-Jacques Pauvert Editeur, 1961. [The Tears of Eros. Traducida por Peter Connor. San Francisco: City Light Books, 1989.]

Carpeaux, Louis. "Découpage de Fou-Tchou-Li”. Péking que s'en va. París: A. Maloiné, 1913: 184-191.

Cortázar, Julio. Rayuela. Buenos Aires: Editorial Sudamericana, 1970.

Dumas, Georges. Nouveau traité de psychologie, tomo 2 (París: Librairie Felix Alcan, 1932): 283-286.

Elizondo, Salvador. Camera lucida. México: Joaquín Mortiz, 1983.

Farabeuf. Barcelona: Montesinos Editor, 1981. Primera edición, México: Joaquin Mortiz, 1961.

El grafógrafo. México: Joaquín Mortiz, 1972.

El hipogeo secreto. México: Joaquín Mortiz, 1968.

Fouques, Bernard. "Farabeuf, entre l'anatheme et l'anamorphose". Bulletin Hispanique 83, 3-4 . julio-diciembre de 1981, 399-431.

Granet, Marcel. La pensée chinoise. New York: Arno Press, 1975.

I Ching: El libro de las mutaciones. Introducción y traducción del chino al alemán de Richard Wilhelm. Prólogos de C. G. Jung y Hellmut Wilhelm. Introducción de Richard Wilhelm. Traducción del alemán al español de D. J. Vogelmann. México: Editorial Hermes, 1983.

Sarduy, Severo. Cobra. Buenos Aires: Editorial Sudamericana, 1983.

Shu Ching. Tomo 3 de The Sacred Books of China: The Texts of Confucionism. Traducido por James Legge. Delhi: Motilal Banarsidass, 1966. 
Walker, Percy. "The Diagnostic Novel: On the Uses of Modern Fiction". Harper's (June 1986): 39-45.

Zola, Emile. The Experimental Novel, and Other Essays. Traducida del francés por Belle M. Sherman. New York, Haskell House, 1964. 